\title{
Development of Faculty of Education of Northeastern University through Professional Learning Community Process
}

\author{
Pha Agsonsua $^{1} \&$ Vanich Prasertphorn ${ }^{1}$ \\ ${ }^{1}$ Northeastern University, Thailand \\ Correspondence: Pha Agsonsua, Northeastern University, Thailand. \\ Received: July 8, 2020 \\ Accepted: July 31, 2020 \\ Online Published: December 7, 2020 \\ doi:10.5430/ijhe.v9n6p318 \\ URL: https://doi.org/10.5430/ijhe.v9n6p318
}

\begin{abstract}
The objectives of this research were 1) to study the present and the desirable condition of the Faculty of Education of Northeastern University, 2) to develop the faculty through PLC process, and 3) to assess the results. The study used PAR (Participatory Action Research) with the sample of selected groups of 6 administrators, 27 instructors, and 378 students with a total of 411 persons altogether. The research results were as follows: Regarding the present condition, the faculty has been traditionally embedded in family culture with the faculty vision of "Being a Professional Learning Community", but, still, seriously underperformed in research work and English proficiency; therefore, the desirable condition was to have research work and English competency meet the national higher education standards that ultimately lead to being professionals. As for the results of the development of the faculty through PLC process and PAR, the research works of all staffs and students were nationally acceptable and published in the journals of TCI group 1 and 2 and looking forward to and now making good progress to international level. Over $85 \%$ of staffs and students passed the Common European Framework of Reference for Language test required by Thai Higher Education Commission. The development will be on-going and moving toward international level. In sum, the development of research work and English competency of the staffs and students in the Faculty of Education of Northeastern University through PLC process and PAR was academically and professionally effective. The study is rewarding.
\end{abstract}

Keywords: professional learning community process, professional development, faculty of education

\section{Introduction}

The world change, so do the management and development of education. Teaching and learning have been changing due to the theories and concepts created at a specific period of the ages. The development of professional learning community is of no exception. It has a long story of continual development that can be traced back to the theories of learning of Thorndike, the world-known psychologist, followed by behaviorists such as Skinner and Gangé. The theory was also strongly advocated and developed by Bruner and Anderson. It was until the recent past that the theory of learning advocated by anthropologist named Vygosky and Vygoskian theory emerged, believing that education is social and cultural process and learning is through the management of social and cultural enterprise. The theory is more clearly verified by the statement of Smith's (1988). Smith stated, "We learn from the company we keep". Learning can be done through "Community of Practice", Brown, Calline \& Duguid (1989).

This concept leads to the practice and belief in professional learning community (PLC) that is strongly supported by all learning communities as practiced in schools of today's world.

Wicharn Pamich (2013) succinctly stated, "Education in the $21^{\text {st }}$ century is not the same as that of the $20^{\text {th }}$ century". The core meaning is that the world is in a rapid and constant change. Knowledge and new learning increasingly and rapidly grow with a great stride and with more challenge. Human relations and types of connections change. Skills needed for leading lives and facing more complexities are changed and varied. The teaching and learning is best fitted through learning by doing with focus on collaboration skills and team teaching rather than ego-self achievement and individual success. This type of learning is attained by self-initiation and awareness. A teacher is the one who inspires and applies the teaching approach of "teach less, learn more". How teachers work changes from lone actors to team collaborators. They collaboratively help setting up a goal for the community of learners to work, live and learn together to enhance collective learning and innovation. The learning is ongoing and directing toward the achievement and success of all engaged individuals. 
The thoughts of Constructivist Group, along with great Thai King's wisdom, including TDRI (Thailand Development and Research Institute) research results indicate that learning is constructed through the process of mutual understanding of the data and information from actual experience - the experience that is embraced and compounded by positive and powerful environment within the context of collegiality and reality. The best suited statement as culled by Vygotsky (1978) is that "learning is effective and valuable when done through experiential activities in social context."

Burns, Menchaca and Disnok (2001) propose 6 key elements of Constructivism which are in confluence with great Thai King's wisdom. Such tenets are respect for individual needs and difference, igniting from the inside out, inspiration and awareness of learners themselves in real learning situation, collective learning through collegiality and collaboration, attraction and assimilation with great learners, feedback and reflection, and then synthesize and crystalize through dialogue, negotiation of the meaning and value for self-knowledge and learner's own concept.

The research results of Thailand Development and Research Institute (TDRI) clearly indicate that teachers development does not respond to the real problems and the real needs of schools. The training is done by external experts or trainers that rarely meet the real problems occurring in actual job performance. Moreover, it is not ongoing to which waste and less effectiveness cause. Closed and continuous process of monitoring and evaluation is then hardly done and thus cause more problems. School-based and job-embedded training and development have come into picture of educational management since then and accepted as relevant and real as the solution to this inherent educational problem. The thought behind this solution is the practice and process of professional learning community (PLC) grounded in the theory of constructivism.

Vescio et al (2007) did a study on PLC characteristic and its values through studying 10 American researches and 1 British research. They cogently concluded, "PLC is an effective process in developing teachers for optimal development of students as the end results." The professional learning community is highly recommended for all educational engagement and management then.

\subsection{Weakness Found in the Faculty of Education}

The results of the assessment of higher education commission showed that there are problems needed immediate and urgent solution and improvement.

Those problems are:

1. The development of research competency of staffs and students are, indeed, crucial. This means quality research, research paper writings as well as academic article writings that must be of fine quality and good enough for publication in journals of TCI group 1 and 2, or be acceptable to be published in well-recognized journals at national and international level such as the Scopus or others of the same quality.

2. The development of English competency for staffs and students are also very acute and badly needed to be improved. From the results of CEFR (Common European Framework of Reference for Language) test required by Higher Education Commission, in 2018 over $90 \%$ of the staffs and students failed.

Being aware of the need and the seriousness of the above-mentioned problems, the research team decided to face the need and solve the problems by using professional learning community process married with participatory action research (PAR). The rationale behind this undertaking is that PLC process and PAR embrace collaboration, shared values and vision, collective learning, collegiality, reflection and feedback, with ongoing and job-embedded process. All activities focus on students' learning which is considered the ultimate goal and end result. The follow-up with monitoring and assessment component of both PLC and PAR are all valuable, essential and appropriate.

Faculty of Education of Northeastern University was originally attached to the Graduate School of the university during the last decade and singled out to establish to be the Faculty of Education by itself in 2016._Fortunately, the faculty has long been in the family culture since the beginning of the program for over 10 years due to the collegial nature of the pioneering staffs. On the re-establishment of the faculty, the vision of the faculty was clearly stated, "Faculty of Education of Northeastern University is a Professional Learning Community Producing Ready-made Graduate for service." The research team found this opportune moment to really look into and study the PLC and its application for developing and solving problems of the faculty.

The faculty comprises 4 degree programs. Those are of undergraduate level such as elementary education, childhood education, and those of graduate level are teaching certificate, masters and doctorate degree in educational administration. The research team has faith and confidence in applying PLC process through Participatory Action 
Research (PAR) to help solving the problems now confronting the Faculty of Education. With strong belief, the team hopes for success undertake the research.

The researcher, as a chair of Doctor of Philosophy in Educational Administration Department with the dean and a senior fellow researcher in the faculty, has strong belief, and confidence in power of the professional learning community process that can help develop and solve the problems of the faculty. Concurrently, Thailand Ministry of Education is also fostering and guiding all education sectors to put PLC into practice. It's the time to have the PLC process to be built in the faculty development programs for solving the above-stated problems.

\subsection{Why Using PLC Process to Help Solving the Problems in the Faculty?}

1. The research team believes that applying PLC process can forge all power and energy of the staffs and students since the PLC is grounded in moral and professional authority, collegiality, shared leadership, shared values and vision and collaboration. The faculty has already been in the nature of family culture since its first establishment as stated earlier.

2. The team also has strong beliefs that both PAR and PLC process share several key common elements that are valuable and useful in addressing the problems now confronting the Faculty of Education. Those key common elements are job-embedded learning and real-life practice, collegial relationships, feedback and improvement, involving analysis, reflection and evaluation. Using this both/and process (PLC and PAR), should yield great results.

To support and confirm the team's belief and faith in the power of PLC and PAR in helping solve and reform educational issues, the research team looked for the authorities in the field and they affirmed "PAR has long been documented in its efficacy as a tool for professional development" (Elliott, 1996; McKernan, 1996; Stenhouse, 1983; Zuber-Skerritt, 1992). Along with the increased attention on professional mastery in the teaching profession, resulting from the implementation of the No Child Left Behind Act of 2001, evolved the understanding of PAR and its value in school improvement and staff development. From the statements of the above authorities it can be interpreted that educators view PAR as valuable and transformative and be of confidence in the impact of PAR on educational implementation. PAR become more proactive in addressing educational issues.

The professional learning community (PLC) model of Rick DuFour and others (Eaker, DuFour, \& Burnette, 2002) shares characteristics with PAR groups. Both are discussed as one central idea with small permutations. Each of the two processes are self-organizing communities demonstrated to benefit participants by increasing professional capacity as well as creating organizational outcomes of merit (Altrichterz, 2005; Eaker et al., 2002; Wenger, 1998, 2004). All two models require a cultural shift to be implemented in school environments of collaboration, collegiality, shared vision, feedback and collective learning.

Writings from members of PLCs, and PAR groups point to a degree of shared identity that develops as the teams mature and their work is successful (Eaker et al., Zeicher, 2003).

It can be concluded that both PAR and PLC are "two in one", and be the one that can help solving educational problems and all challenges with guarantee effectiveness.

After having done a thorough study of professional learning community theory and practice, the team decided to apply participatory action research (PAR) to be married with PLC process which is considered appropriate, feasible and useful. Moreover, the team also believes that this practice and process not only help solving the immediate and urgent problems but will also help improving the culture and climate of the faculty, and of the university as a whole.

With belief, faith and confidence stated above, the research team posited the study and postulated the problem statement as follow:

The objectives of this study were 1) to study the current and the desirable condition of the faculty of education of Northeastern University, 2) to develop research competency and English ability of the faculty staffs and students through PLC process, and 3) to assess the results.

\section{Methods}

The methodology of this research is participatory action research (PAR) using 3 sample groups of the faculty population. Those groups are in administrative position, teaching staffs and students.

The population and sample groups comprised 6 administrators, 27 staffs and 378 students, with total number of 411, using purposive sampling. With regard to content, the research team looked into the theory and practice of professional learning community. Five key elements of PLC process are justified, proposed and applied. Those 5 elements of PLC process are: 
1. Creating shared values, vision and norms

2. Fostering collegial learning and collaboration

3. Building teams for collective learning and professional development

4. Applying shared and supportive leadership

5. Providing reflection, dialogue and feedback

The research comprised 4 steps.

Step 1: Study the theory, principle, best practice, related research findings, related literature, texts, academic articles, dissertations and theses, online information, proceedings and seminal work. After searching and sorting the information and data needed, the team discussed and formulated the conceptual framework of the research. The conceptual framework is shown below.

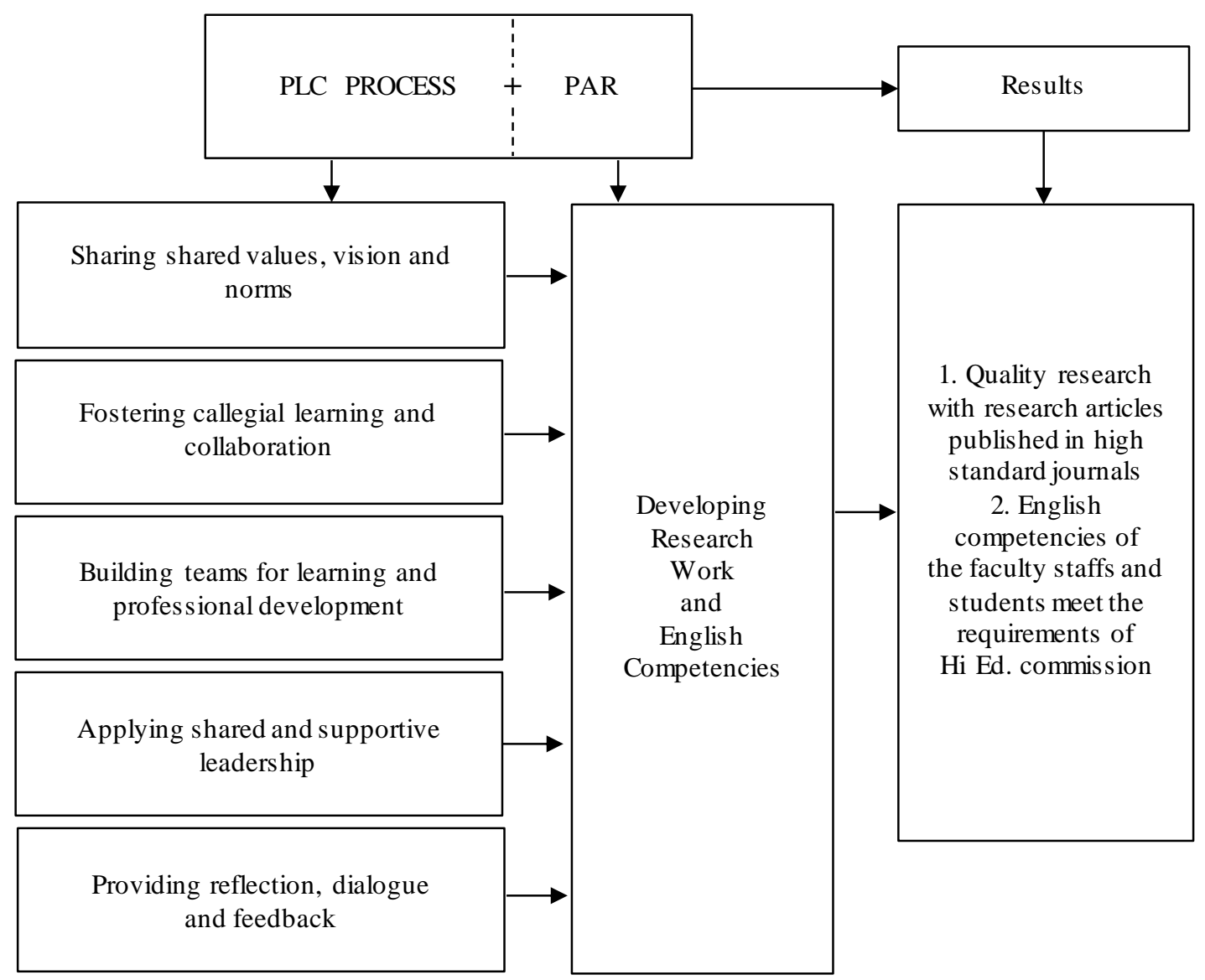

Figure 1. Research Conceptual Framework

Step 2: Awareness building. This step was to have all participants, especially the key ones, get the idea, understand and realize the importance and the usefulness of PLC and PAR process. To ensure profound understanding, awareness and engagement, the research team collaboratively organized meetings, conferences, study visits and learning from best practices.

Step 3: Two workshops were organized by the team and another two were done by the key members of the faculty. Each workshop took 50 participants. Two study groups of research and English were initiated mobilized and organized.

The meetings, workshops and discussions were recorded and documented. The major undertakings of this step were planning, plan implementation, follow-up and evaluation. The evaluation was done to ensure enough understanding and awareness of the power and benefits of PLC process and PAR approach. There were also dialogue, feedback and 
reflection among research team members, key staffs and students studying the problems and how to address them. The end result was also the concern, real focus and realization of all related parties.

Some key activities undertaken all through the study were:

1. Using all kinds of meetings whether regular, monthly, weekly, formal or informal, to help members learn, lead and share or even to test patience, tolerance and courage, feedback taking and giving, and resilience.

2. Peer coaching and working in small groups through doing researches in teams, helping each other in studying and practice doing and presenting research papers in groups or in classes.

3. Using English in various occasions as much as possible in class, in office, in play and all gatherings, all conversations geared to English improvement and research betterment.

4. Attending professional meetings, conferences and workshops that request participants to present research papers in English in particular.

5. Critical Friends Groups, Learning Circles, Study Groups, Book Studies are being initiated and now in ongoing practice. Self-directed learning is also encouraged and required.

6. Taking courses of research in education and intensive English for graduate studies, English for educators.

7. Journaling, reflection, evaluation, feedback are organized and encouraged, use evaluation and assessment as key drivers of learning and improving both research competency and English proficiency.

8. Close connection with Khon Kaen University and other higher education institutions, and other related agencies noted for research and English teaching, sharing expertise and experience.

9. Learning from observing oral exams of doctoral candidates or of the masters or any focus group discussions of students' dissertation or thesis.

10. Actual practice of writing research abstract and quality research papers under close supervision of experts or specialists in the field. Presenting papers in conferences, seminars and or requesting for publication of highly recognized journals nationally and internationally. Now focusing on writing in English to be published in international journals.

Step 4: Focus Groups Discussion. There was a focus group discussion of 10 experts to help refine, improve and approve the study, the comments and suggestions were recorded also taken into deliberate consideration and put into actual practice. The appropriateness, feasibility and utility of the study were all positively affirmed with encouragement, hope and promise.

\section{Results}

With regard to the current and the desirable condition of the faculty development, the faculty still has acute problems with research quality and English competency of staffs and students. The problems need urgent solutions since both the quality of research and the competency in English of the staffs and students are far below standards required by Thai Higher Education Commission. Because of these critical problems the desirable condition must be developed and be undertaken urgently. The desirable condition is rated at the highest level of need. The quality of research must meet the national standard and be of internationally acceptable to be published in highly recognized journals worldwide if the faculty is to survive.

After 2 years of this study, it is evident that the results of applying PAR \& PLC process to help develop research quality and English competency are successful and fulfilled. The research articles of the faculty staffs and students, those of Ph.D. students in particular, have been all accepted and published in journals with TCI group 1 and group 2 since 2018. Those of the masters and the teaching certificate levels are also accepted and published in journals with TCI of group 2 and some of group 1.

As for the improvement of English competency, all of the staffs and the students in the faculty passed the CEFR (Common European Framework of Reference for Languages) test and met their degree requirements for graduation which also met the standards required by Thai Higher Education Communities. The main causes of the success are family culture, collegiality and collaboration, distributed leadership, shared values and vision and supportive structure and context. The faculty dean and all high administrative leaders are also key factors of success. They are all quite supportive. The research team and key staffs are very important catalysts. Their great mind and high spirit with shared vision and values, leading by examples, inspiration and determination are all great causes of the achievement. 


\section{Discussion}

The lessons learned from this research study are immense and valuable. The most valuable and the most essential elements in all learning community development are trust, respect, growth mindset, risk-taking, commitment, courage and resilience and some other values. Take trust for an example, trust is a glue and cement to hold things and human beings together. We must have trust in ourselves, trust in others and also trust in the process. Mutual trust and relational trust are among the most valuable ingredients for successful and effective learning and living together. For those who are imbued with growth mindset are great learners in professional learning community. It takes open-mindedness and courage to accept failure and threatening feedback. We learn how to be resilient, to be easy with risks and mistakes. We dare to learn from mistakes and to feel strong in the face of inadequacy. We grow and be able to live in a "No Blame, No Shame" culture.

Among the very valuable wisdom we learn and earn is "Hedgehog Concept" asserted by Collins (2005). He identifies hedgehogs as those who keep looking at the goal and don't get distracted, whereas those he calls "foxes" keep jumping around from one thing to another. Hedgehogs keep focused on making decision with their most important values and vision in focus. Keep the eyes, ears, head and heart focused on learning for solving problems and for betterment through PAR and PLC process is not for the heart of faint. It takes courage, commitment and the heart for any fate.

One of the most important essence as key instrument that impacts the faculty most is an ongoing conversation on the study and the subject in focus. In our daily conversation, learning is our main point, especially learning English along with developing research competency is our faculty business, our faculty product and our faculty (community) process. We encourage and engage in deep and active listening, setting aside judgment, practical and valuable questions, staying open, with clarity of goal in mind as suggested and insisted by Hord (2008)

In addition to conversation, we apply dialogue, reflective dialogue in particular. As stated earlier, our faculty holds on to the family culture as stated in our faculty vision - "Our faculty is a professional learning community". Dialogue is our norm and our nature and it is of great value for our faculty gatherings and learning from groups.

The five key ingredients forged in the PLC process proposed in this study are useful and powerful forces for developing the faculty of education or even any type of communities. One of the most potential and the most essential ingredient, found in this study, is shared and supportive leadership. It is supported by the statement of Leithword, et al (2004), "Next to teacher quality, leadership and school culture have the most effect relative to student learning". A leader must be a head learner who also develop other leaders. Another perceptive comes from Spillane (2006) stating, "Leadership in school requires a network of formal and informal leaders working together for common goals. The interactions between formal and informal leaders are indicative of collaboration and a focus on learning". Leadership as partnership as asserted by Maxkey (2000) in Leadership and Spirit is evident and realized in our community. The concept is immensely impressive and really useful. We are all of equal worth and importance. It breeds collaboration and collegial support. Sharing wealth, sharing wisdom and repertoire are the faculty norms. We learn and live together with respect, trust and confidence in each other. We are of one family in the same boat on our journey to our destination which English and research competency are our ideal results are intended. We are leaders among leaders.

\section{Conclusion}

Our research concludes that PAR is a powerful tool in addressing educational difficulties and challenges. As a research methodology, it holds the capability to take complete situations which need an ongoing process and be of continuing in cyclical nature. Action in concert or participation or collaboration in nature that is also the heart and soul of PLC. We find PAR married with PLC very valuable, powerful in helping develop and improve our faculty. The next task that we feel of great courage and pledge to extend and expand our study is to finish our professional development to make all our faculty members the real professionals and succeed beyond the call of the required standard. The job is not easy but it is inspiring and most of all, rewarding. The job is just beginning and hopefully we all will altogether take the long and winding road ahead of us with the hedgehog concept and great growth mindset in learning--learning for us all, for our beloved friends (our students).

\section{References}

Altrichter, H. (2005) et al. The Role of the Professional Community in Action Research. Educational Action Research, 13(1), 11-26. https://doi.org/10.1080/09650790500200274 
Burns, M., Menchaca, M., \& Dimock. V. (2001). Applying technology to restructuring and learning. Paper presented at 2002 Computer Supported Collaborative Learning (CSCL) Conference, Pedagogy track: Teacher and CSCL., Boulder, Colo. https://doi.org/10.3115/1658616.1658656

Cochran-Smith, M., \& Lytle, S. L. (1999). Relationship of knowledge and practice: Teacher learning in communities. In A Iran-Nejar, \& P. D. Pearson (Eds.), Review of research in education (pp. 249-305). Washington, DC: AERA. https://doi.org/10.3102/0091732X024001249

Collins, J. (2005). Good to Great and the Social Sector: A monograph to accompany Good to Great. Boulder, CO: Author.

DuFour, R. (2004). What is a Professional Learning Community. Educational Leadership. 63(8), 6-11.

Eaker, R., DuFour, R., \& Burnette, R. (2002). Getting Started: Reculturing Schools to Become Professional Learning Communities. Bloomington, IN: National Education Service.

Elliolt, J. (1991). Action Research for Educational Change Milton Keynes, UK: Open University Press.

Farson, R., \& Keyes, R. (2002). Whoever Makes the Most Mistakes Wins. New York: Free press.

Fullan, M. (2001). Learning in a Culture of Change. San Francisco: Jossey-Bass.

Hord, Shirley M. Sommers, (2008) William A, Leading Professional Learning Communities. California: Corwin Press.

Lambert, L. (1998). Building Leadership Capacity in Schools. Alexandria, VA: ASCD.

Leethwood, K., et al (2004). How Leadership Influences Student Learning. Minneapolis: University of Minnesota, Center for Applied Research and Educational Improvement; Toronto, Ontario Institute for Studies in Education.

McKurnan, J. (1996). Curriculum Action Research: A Handbook of methods and Resource for the Reflective Practitioner $\left(2^{\text {nd }}\right.$. ed. $)$. London: Kogan Page.

Panich, Wicharn (2011). Construction of Learning for $21^{\text {st }}$ Century, First Publication. Bangkok: Tathata Publication.

Pongboriboon, Yarjai (2007). Qualitative Research. Khon Kaen: Research and Development Division, Northeastern University.

Sergiovanni, T.J. (1994). Building Community in Schools, San Francisco, CA: Jossey Bass.

Smith. F. (1988) Joining the Literacy Club, Portsmouth NM: Heinemann.

Sod-iem, Pimorn (2012). Development of Linear Relationship Model of Factors Affecting Professional Learning Communities in Secondary Schools, Full Report. Loey: Faculty of Education, Rajabhat Loey University.

Somprach, Kanokorn (2015). Leadership and Learning Leadership for School Principal. Khon Kaen: Faculty of Education, Khon Kaen University.

Spillane, J. (2006). Distributed Leadership. Sanfrancisco: Jossey Base

Srisaad, Boonchom (2003). Basic Research, $7^{\text {th }}$ ed. Bangkok: Suriyasarn.

Strahan, D. (2003). Promoting a collaborative professional culture in three elementary schools that have beaten the odds. The Elementary School Journal, 104(2), 127-146. https://doi.org/10.1086/499746

Targkitvanich, Somkid (2013). Implement All Aspects of Educational Reform. Bangkok First published in The Nation Website. 21-3-2013. under TDRI: Thailand Development Research Institute.

Tunmuntong, Sunthorn (2012). Alternative Schools And Innovative Learning in Thailand. Bangkok: Creative Commons. 20-8-2012. under TDRI: Thailand Development Research Institute.

Vicki Vescio, Dorenc Rose, Alyson Adams, (2007), A Review of Research on the Impact of Professional Learning Community on Teaching Practice and Student Teaching, Science Direct, Teaching and Teacher Education, 24(2008), 80-91. https://doi.org/10.1016/j.tate.2007.01.004

Vygotsky, L. S. (1978). Mind in Society: The Development of Higher Psychological Process. Cambridge: MA: Harvard University Press.

Wenger, E. (1998). Communities of Practice. Cambridge, UK: Cambridge University Press. https://doi.org/10.1017/CBO9780511803932

Wongwanich, Suwimol (2007). Needs Assessment Research. Bangkok: Chulalongkorn University Press. 
Zeichner, K. (2003). Teacher Research as Professional Development for P-12 Educators in the USA. Educational Action Research, 11(2), 301-326. https://doi.org/10.1080/09650790300200211

Zepeda. S. (2012). Professional Development - What Works, New York: Eye on Education. Thousand Oaks, CA: Corwin Press.

\section{Copyrights}

Copyright for this article is retained by the author(s), with first publication rights granted to the journal.

This is an open-access article distributed under the terms and conditions of the Creative Commons Attribution license (http://creativecommons.org/licenses/by/4.0/). 